\title{
Remembering the Troubles through stitch, sound and word
}

\author{
Authors: Eileen Harrisson $\nabla$, Aberystwyth University, UK
}

In 2013, I obtained an MA in Art and Art History at Aberystwyth University and I am currently studying part-time for a PhD in Fine Art, in which I am exploring the symbiotic relationship between stitch, sound and word through the prism of my experiences of the Troubles in Northern Ireland. A freelance artist, I take part regularly in exhibitions in the UK and abroad and with poems published, I give readings and performances of my poetry at a variety of events. My work involves wall hangings, artist books and installations and I also write music and collaborate with my son, Edward Harrisson, on music and films. I was awarded funding from the Arts Council of Wales for the musical element of an installation. Married with a grown-up daughter and son, I live with my husband in Snowdonia, N. Wales.

\section{Abstract}

This article discusses how the medium of hand stitch in relation with sound and the poetic word brings particular properties to the act of remembering. It explores what it means to document remembered events verbally and through art and the rôle played by the senses, including that of hearing, prompted by the medium of textile. The nature of the experience of trauma is addressed and what personal recollection can bring to the understanding of the affects of conflict on society, including vulnerable groups such as children, and how stitched work is a metaphor for the act of healing.

Keywords: Stitch, Troubles, Art, Poetry, Sound, Healing

\section{Introduction}

I was born and grew up in Co. Down, Northern Ireland and, after attending a state girls' grammar school, graduated from Aberystwyth University in 1975 with a Joint Honours BA in Art and Italian. I then returned to Northern Ireland in part because of the severity of the illness which had seen my father invalided out of the RAF during World War II, working in Belfast at the height of the Troubles until my marriage in December 1981 entailed a move to England. My work in Belfast meant that I experienced at first hand the effect of almost daily bombings on the body, mind and psyche and, through the haptic tactility of the medium of stitch, a medium practised mostly by women, this personal history brings the voice of the feminine within the masculine narrative of conflict. 
The Civil Rights March, Londonderry, in 1968 is regarded as the beginning of the violence that was to affect every aspect of life in Northern Ireland but it was not until much later when I embarked on my $\mathrm{PhD}$ in Fine Art at Aberystwyth University that I began to explore my experiences of this time through art. My initial creative response to the Troubles manifested itself as poetry and this poem, 'Lagan 1995', was written to express the hope that a way might be found to end the violence of the extremist groups that had been tearing Northern Irish society apart for at least three decades:

Red river, blood river, flotsam of the dead river, creep around ships in harbour, pull yourself to the mother sea, water salt-bright as tears. Pax vobiscum in the silver chalice; is this really the end to fear? Spewed over hate-erupted fires, a new bridge is slung over your cold meandering; can peace so easily close the screaming lips of gangrenous jealousy, mistrust? Broken small child weariness says it should; ubi caritas et amor says it must.

The Good Friday Agreement in 1998 succeeded in setting out a plan, which allowed both loyalists and nationalists to work together on a path toward resolution but when a cruel killing shattered the level of peace so dearly bought, I revisited the issues in my earlier poem to write 'Belfast: Lagan revisited' which opens with the lines:

It was black and red then, shadows darker than coal blood-bright puddles reflect flames shooting high, colour the night sky. 


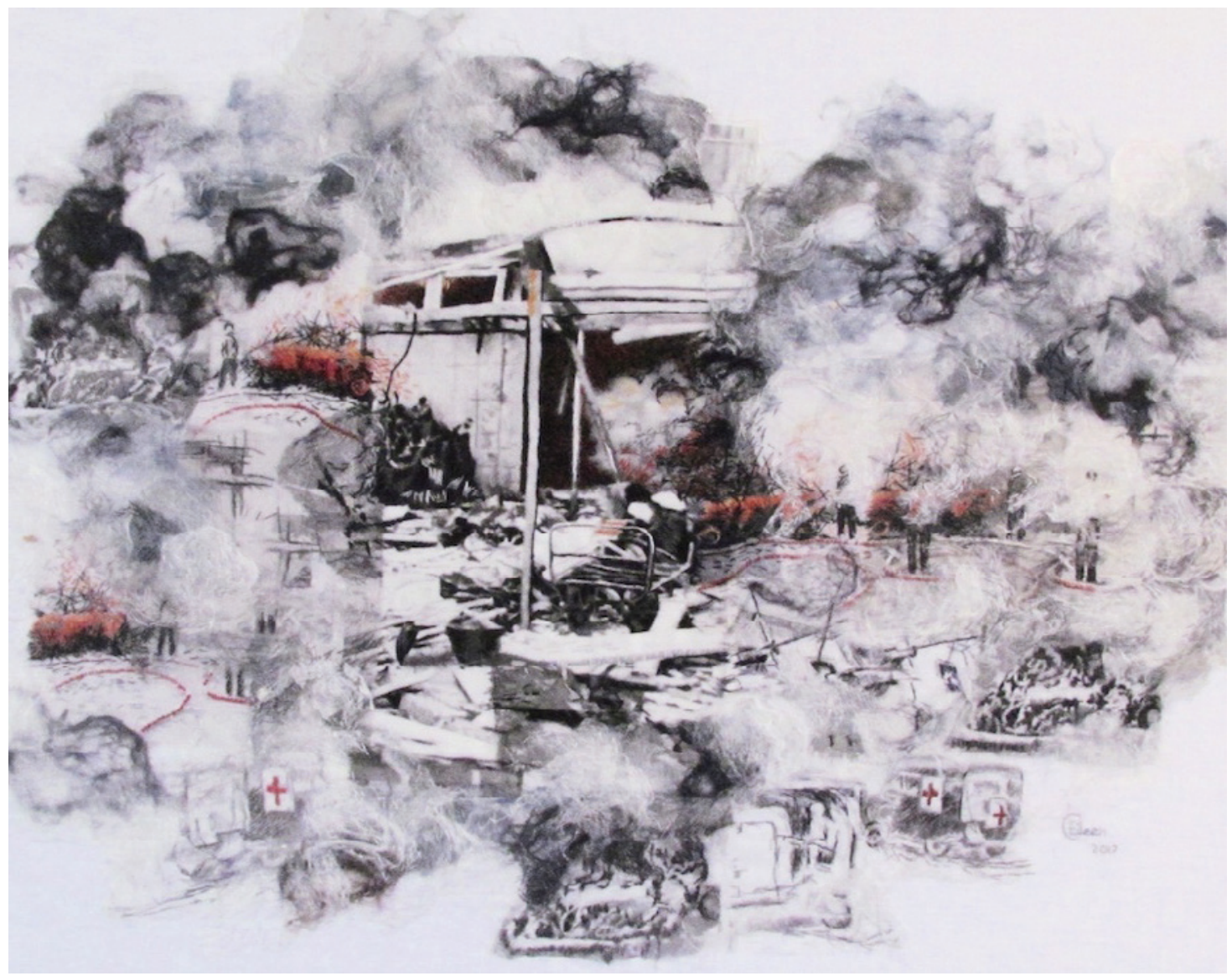

Figure 1 - Litany

One evening, I walked home after work in Belfast Central Library through a city rocked by multiple explosions, and the poem paints a verbal picture of the fires that blazed and the billowing smoke; later, this image of smoke became one of my most enduring memories of living through the Troubles. My nights of trying to sleep were often punctuated by recurring memories of the bombings and it was through interpreting these memories in stitched artworks, such as Litany (Figure 1), that the therapeutic act of pulling thread through cloth began to give solace to the injured psyche. In my poem 'For the others', I write of how, remembering the victims of the bombings

...I hear their cries sorrowing in my head, so I stitch paths of remembrance, red veining in lines of silk and cotton,

blood red threads that are life and death and hope and grief and resurrection. 
We are wrapped in cloth when we are born, wear clothes all our lives and are again dressed when we die; a network of hand stitches forms the billowing smoke of Litany and, unlike an oil painting or watercolour, the stitched work connects us to the image in an unspoken physical relationship with the materiality of its production. In addition to this physical connection with the body, connotations of domesticity may also be brought to mind through recollections of family members carrying out sewing in the home. The bombings that this artwork and others such as Futility reference, wounded the body and the psyche. The artworks bring the impact of the visual within the historical recording of the period and perform the role of protest against this injuring of others.

As well as stitched and painted sections, the work Continuum introduces mirror shards applied within the collaged artwork (Figure 2). These reflective surfaces act to pull the viewer closely within the field of the artwork, inviting him or her to bring their own memories and experiences to the subject matter depicted and so the viewer, male or female, is no longer simply a spectator; through the pull of the artwork, they are participants in the memories of violence. Women are now deployed as soldiers alongside their male colleagues but, despite this, conflict is still regarded as largely masculine and the domestic sphere as mainly feminine; thus, to produce images of war in the gentle medium of hand stitch is to bring the feminine within the field of the masculine. In addition to these associations, the importance of the linen industry to Ireland and to Belfast in particular (William Clark and Sons, 2015), including members of my own family, means that a work stitched on a linen base introduces connotations of social and economic history within the field of the violent events.

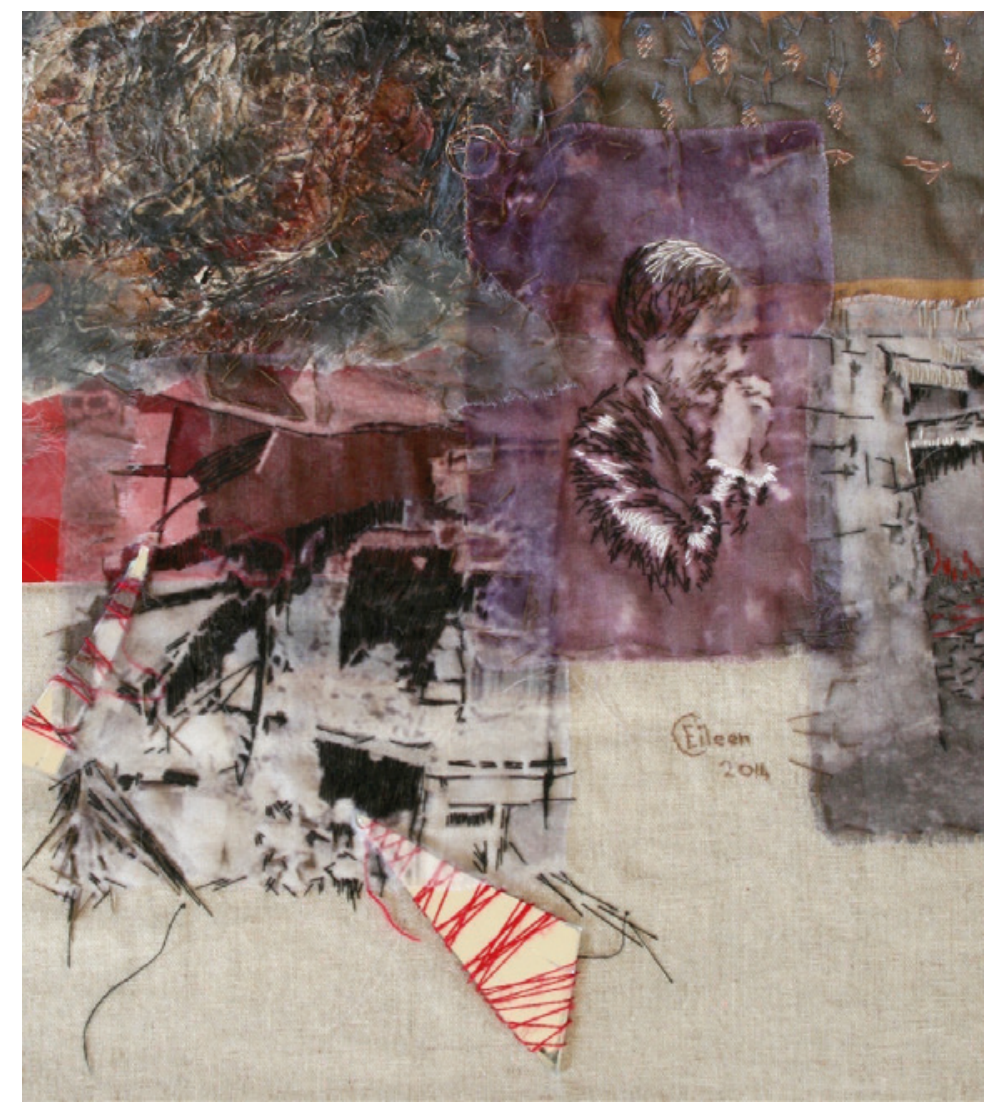

Figure 2 - Continuum

In the years following my move to England, I was surprised by how often diverse people I met asked me to describe "what it was like" in NorthernIrelandduring the Troubles. Events were reported on television but it seemed people wanted to hear the personal experience, and this led me to consider the meaning of the passage of time in regard to experiencing conflict and how we approach it verbally and through art. In communicating the story of a violent event, the narrator not only recalls the experience but in the retelling, re-lives the moment, a re- 
living that political scientist Professor Jenny Edkins calls 'trauma time' (Edkins, 2003, pp. 15-16). This 'trauma time' is more vivid than a simple recollection, in that the person feels themselves transported back to the moment of the original incident, so the act of traumatic remembering breaks down the confines and barriers of chronological time. To produce an artwork based on memory is to realise it in concrete form and to do this through the medium of stitch brings not just a haptic materiality but, in addition, the power of sound.

When I began my doctorate investigations, I was exploring the physical properties of textiles and in the course of this, I pulled a single strand of linen thread through calico fabric stretched in a hoop. The power of this sound took me by surprise and when accentuated on the computer, the loud growling rasp transported me to the streets of Belfast in the aftermath of a bombing. As the sense of smell can transport us vividly to re-live past moments, so the sense of hearing gave a similar experience to me through the unexpected properties of cloth. Artist and author Salomé Voegelin writes of how sound enters our bodies in a visceral way that the visual image cannot do (Voegelin, 2010, pp. 46-47) and, with my chosen medium now speaking through hearing as well as seeing, I adopted this quality further through a connection with my poetry. In my stitched works, I build up layers of transparent and opaque fabrics to construct the image and, mirroring this method in sound, I recorded different voices reading lines from my poem 'Fragments', overlapping them to flow in and out of one another. These voices, both male and female, came from Ireland, England and America, encompassing the different places that played a part in the Troubles and their resolution. The soundtrack created was made available for exhibition visitors to access via headphones and it was placed beside the stitched piece Litany, as these two works in particular echo one another in process. I also perform my poetry at exhibitions and other events, bringing the intonations of the human voice to play alongside the artworks presented. Through image, the textile medium and sound, works invite discussion of the political situation of conflict as it unfolds throughout history, something which was brought together dramatically in vision, word and sound in the wall hanging and film Continuum which considers how, as one dispute finds a level of reconciliation or resolution, another bursts into violent life.

One of the aspects of the Troubles that I found most disturbing was the suffering of children, and I visualised this through the image of a crying child repeated across the surface field of Continuum, as seen in Figure 2. This work featured in the exhibition Stitched voices (Conflict Textiles, 2017) shown in the Aberystwyth Arts Centre under the aegis of Roberta Bacic of Conflict Textiles (2017), and in the Roe Valley Arts and Cultural Centre, Limavady, Co. Londonderry. As the title suggests, it includes images of conflict that encompass combatants from the First and Second World Wars to Northern Ireland's Troubles in the late twentieth century. This exhibition was dedicated to giving a voice of resistance against the killing, grief and trauma of war, and the horror of people 'disappeared' through political regimes governed by dictatorship and total disregard toward the suffering of others. 
Roberta Bacic invited me to write a poem inspired by my artwork, and this poem features in my film Continuum (Harrisson, 2018) made in collaboration with my son, the professional musician Edward Harrisson. Music can speak with a voice that reaches to the heart of the listener and, with a lifelong love of and involvement in music, I have experienced physically the vivid impact of synaesthesia. This pulling together of sound with colour has been enhanced through my working with stitch; I find stitch leads to words which lead back into further stitch and, as the works progress, the images start to speak in a musical cadence, often, owing to the tragic nature of the conflict depicted, in the key of G minor. I have said how I find carrying out the rhythms of hand stitch in particular to be a therapeutic process; stitch is used to staunch the flow of blood to help heal wounded flesh. In a similar way, a needle pierces cloth in a stabbing action to form a stitch but the network of stitches then heals the "wounded" fabric.

Connotations can be found here of the compassion of the healing profession, a profession I was privileged to work in for a short time; I have stitched the image of a young woman, a passer-by, going to the aid of a man injured by an explosion on both my piece Continuum and on the base of my three-dimensional work, The nurse's cape (Figure 3), this cape which carries my stitch having previously belonged to a nurse from the Royal Victoria Hospital, Belfast. Human voices singing in the minor key, colour in the red of flame and blood, the black of dense smoke and mourning, the meditative act of stitch, and poetic words of sorrow and hope come together in my film Continuum in a lamentation that reaches out to the spectator/receiver in a holistic expression of the tragically dramatic impact of civil conflict on humanity. 


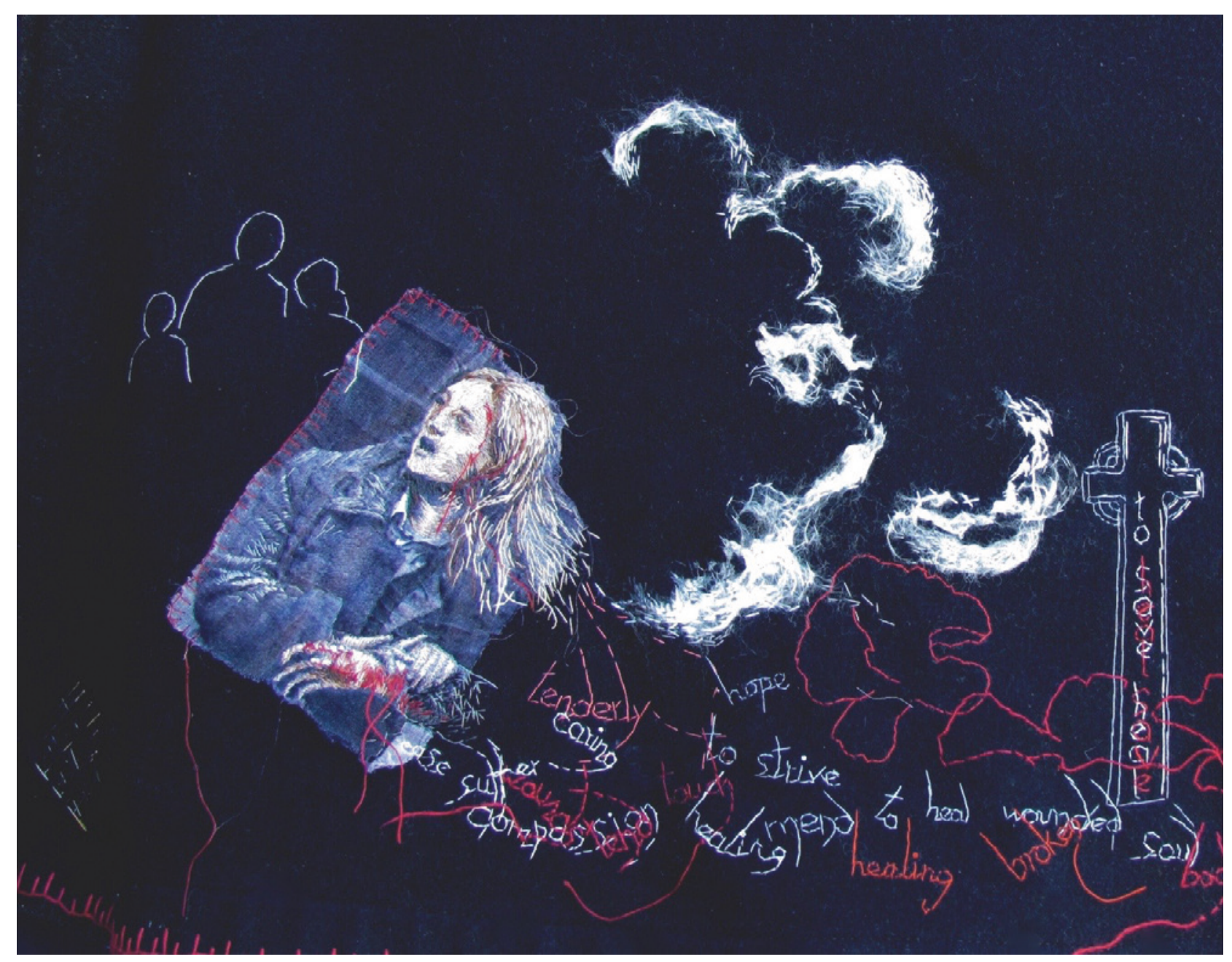

Figure 3 - The Nurses Cape

My sorrow at the death of children in conflicts is not confined to my home country. In the autumn of 2016, I found myself deeply affected by a news report about the city of Aleppo in Syria. This report told of how three children, a toddler and her two older brothers, were playing on the balcony of their home by their school at break-time when they were hit by shell-fire and killed. My piece Her pillow, the earth (Figure 4) shows a small child asleep and poses the question, is she a refugee asleep on the ground or has she been killed and the earth is her pillow in death? The tragedy of those children in Aleppo mirrored in the present time the tragedy of the children who had died some years before in the Troubles. This work was exhibited in War-torn children (Conflict Textiles, 2018), an exhibition in which artists brought to light, as with Stitched voices, the suffering war inflicts, this time on children, with images of child victims from the Second World War to the present century. These artworks demonstrate how art crosses borders of both time and nations, and how it brings vividly into the public consciousness the plight of the most vulnerable in society. This voice of political activism was heard again through the exhibition Conflict, famine and displacement, then and now (2020). 


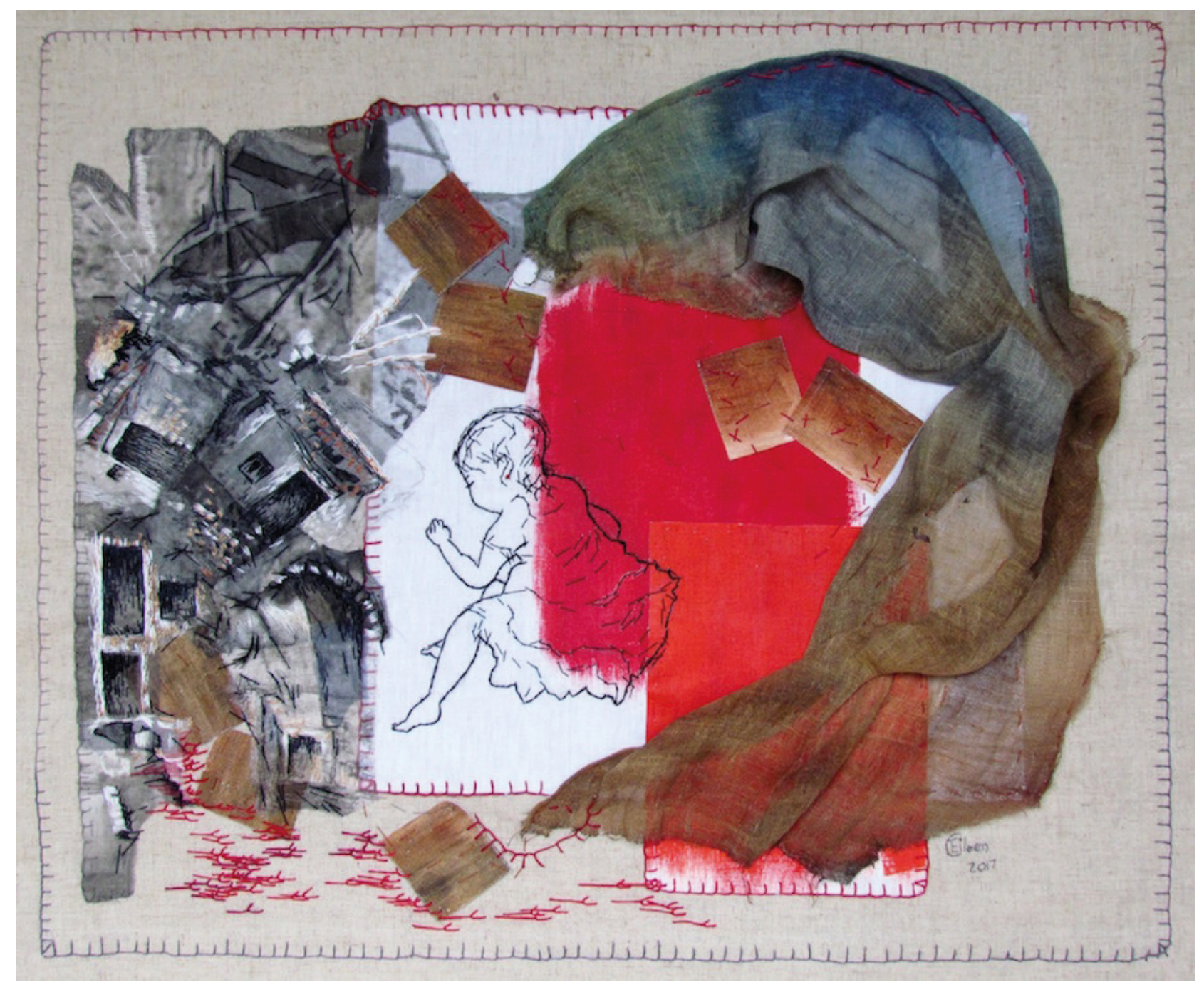

Figure 4 - Her pillow the earth

\section{Conclusion}

My work in stitched pieces, poetic word and musical sound documents my experience of conflict and puts forward empathy toward others caught up in the throes of grief and pain that violence beyond their control brings. Compassion at another's suffering is not destroyed by actions of violence, as visualised by the artworks and expressed poetically and musically in the film Continuum. A sleeping child, this time a little boy, is again placed at the centre of another stitched artwork entitled $A$ sacrifice too great. This title sums up the aims of all my work on conflict; through documenting the experiences of one woman, I hope to paint a picture of pain but also of hope that art can be a voice that says how violence pays too great a price to achieve political ends and that what matters in this life is, always and through every act we make, to show love.

\section{Bibliography}

Conflict Textiles (2017) Continuum [Online]. Available at: https://cain.ulster.ac.uk/ conflicttextiles/search-quilts2/fulltextiles1/?id=371 (Accessed: 25 August 2020). 
Conflict Textiles (2018) Her pillow, the Earth [Online]. Available at: https://cain.ulster.ac.uk/ conflicttextiles/search-quilts2/fulltextiles1/?id=390 (Accessed: 25 August 2020).

Edkins, J. (2003) Trauma and the memory of politics. Cambridge: Cambridge University Press.

Harrisson, E. (2018) Continuum - Come stay, 2 January [Online]. Available at: https://www. youtube.com/watch?v=BTg20b00s-Y (Accessed: 24 February 2020).

Voegelin, S. (2010) Listening to noise and silence: towards a philosophy of sound art. New York: The Continuum International Publishing Group Inc.

William Clark and Sons (2015) 'A history of Irish linen', 23 December [Online]. Available at: http://www.wmclark.co.uk/a-history-of-irish-linen/ (Accessed: 25 August 2020). 